
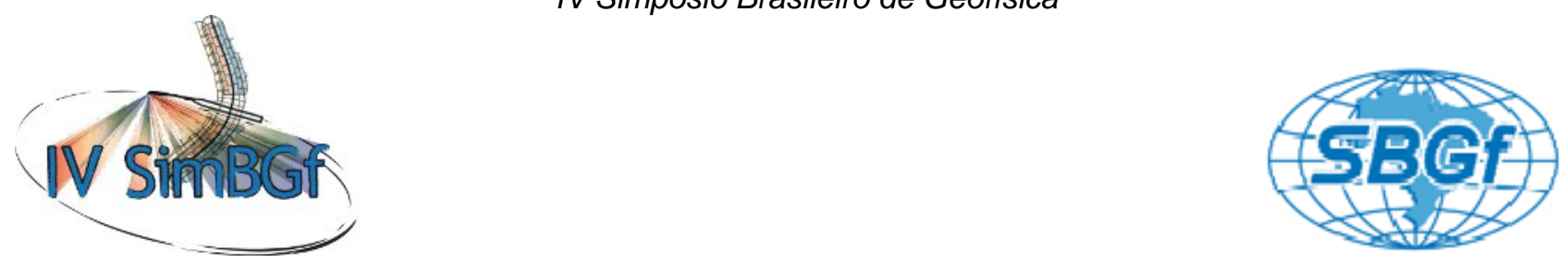

\title{
Interpretação sísmica das principais feições estruturais da llha de Itaparica, Bacia do Recôncavo, Brasil.
}

*Moisés Vieira Pinto ${ }^{1,2}$, Marco Antônio Barsottelli Botelho ${ }^{1}$ e Luiz Cesar Corrêa-Gomes ${ }^{1}$

${ }^{1}$ Instituto de Geociências - CPGG- UFBA

${ }^{2}$ Agência Nacional do Petróleo, Gás Natural e Biocombustíveis

Copyright 2010, SBGf - Sociedade Brasileira de Geofísica

Este texto foi preparado para a apresentação no IV Simpósio Brasileiro de Geofísica Brasília, 14 a 17 de novembro de 2010. Seu conteúdo foi revisado pelo Comite Técnico do IV SimBGf, mas não necessariamente representa a opinião da SBGf ou de seus associados. É proibida a reprodução total ou parcial deste material para propósitos comerciais sem prévia autorização da SBGf.

\section{Resumo}

A Ilha de Itaparica, localizada no nordeste do Brasil e mais especificamente no recôncavo baiano, situa-se geologicamente no extremo sul da bacia do Recôncavo, sendo considerada na literatura como zona limítrofe entre as bacias do Recôncavo e Camamu, sendo a falha da Barra a estrutura geológica limitante. Esforços exploratórios para óleo e gás realizados principalmente nas décadas de 60 e 70 forneceram a maior parte do acervo de dados geológicos e geofísicos da região, estando a indústria do petróleo local limitada hoje ao Campo de Itaparica, já maduro, e à acumulação marginal de Morro do Barro, ambos com atividade exploratória praticamente inexistente. A interpretação de linhas sísmicas onshore e offshore permitiu observar o sistema de falhas da Barra tanto na região da Ilha quanto na costa atlântica em direção à falha de Salvador, limite oriental da bacia do Recôncavo. A interação entre a geologia de superfície com dados sísmicos de reflexão subsidia uma discussão acerca do arcabouço tectônico da Ilha de Itaparica

\section{Introdução}

A bacia do Recôncavo localiza-se no estado da Bahia, Nordeste do Brasil, ocupando uma área de aproximadamente $11.500 \mathrm{~km}^{2}$ sendo parte integrante do rifte Recôncavo-Tucano-Jatobá. Seus limites atuais são representados pelo alto de Aporá, a norte e noroeste; pelo sistema de falhas da Barra, a sul; pela Falha de Maragogipe, a oeste; e pelo sistema de falhas de Salvador, a leste (Silva et al., 2007). De acordo com Caixeta et al. (2007), o limite norte da bacia de Camamu com as bacias do Recôncavo e Jacuípe é dado pela falha da Barra, uma importante feição regional que corta a bacia na direção leste-oeste.

Apesar de a área de estudo estar em sua maior parte localizada na bacia do Recôncavo, a qual é a província petrolífera mais antiga do país e, conseqüentemente, uma das mais estudadas, existe uma carência de informações disponíveis de domínio público, estando os principais estudos restritos às empresas que atuam ou atuaram na área. Este trabalho apresenta resultados preliminares da interpretação das seções sísmicas existentes na região, integrando-as com informações geológicas existentes, procurando entendimento geológico para a região da llha de Itaparica, bem como a implicação estrutural e estratigráfica do Sistema de Falhas da Barra no contexto geológico regional.

\section{Contexto Geológico Regional}

A llha de Itaparica está inserida no limite entre as bacias do Recôncavo e de Camamu (Figura 1). Geologicamente, o limite entre as duas bacias se dá pelo sistema de falhas da Barra. Na porção da Ilha, destaca-se o horst de Itaparica, onde as seqüências do pré-rifte e o embasamento cristalino encontram-se a profundidades bastante inferiores em relação às posições que as mesmas ocupam na porção sul, no domínio da Bacia de Camamu.



Figura 1 - Contexto geológico regional do extremo sul da bacia do Recôncavo e sua localização no estado da Bahia.

O embasamento cristalino é caracterizado por rochas gnáissicas - granulíticas, aflorantes na borda leste da bacia. De acordo com Alkimin (2004), o embasamento da região pertence ao Cinturão Proterozóico do Leste da Bahia, constituinte do Cráton do São Francisco, cujos terrenos foram estabilizados a mais de $1.8 \mathrm{Ga}$. Segundo Barbosa e Corrêa-Gomes (2003), as bacias de Camamu e Sul do Recôncavo estão instaladas no domínio do Orógeno Itabuna-Salvador-Curaça. 
De acordo com Destro (2002), a feição mais marcante do Rifte do Recôncavo-Tucano-Jatobá é a inversão na assimetria dos semi-grabens constitutivos ao longo de sua direção. O semi-graben da bacia do Recôncavo possui direção NE-SW e mergulha para SE, consistindo da falha de borda de Salvador, cujos deslocamentos atingem $6 \mathrm{~km}$ e de um conjunto de falhas normais sintéticas e antitéticas, orientadas na mesma direção.

Além das falhas de borda, importantes feições estruturais são marcantes ao longo de todo o rifte RecôncavoTucano-Jatobá, a exemplo das falhas transversais de Mata-Catu, Cassarongongo e outras, amplamente estudadas por Magnavita (1992), Aragão (1999), Destro (2002), Destro et al. (2003), entre outros.

O arcabouço estrutural da área de estudo é limitado, a oeste, pela falha de Salvador, estando a mesma bem marcada em seções sísmicas NW-SE, e fortemente influenciado pelo sistema de falhas da Barra, marcado por falhas transversais que separam as bacias do Recôncavo (a norte), Camamu (a sul) e Jacuípe (a leste). Densas discussões a cerca do conceito de falhas transversais e explanação das principais falhas transversais do rifte Recôncavo-Tucano-Jatobá, a exemplo das falhas de Mata-Catu, Cassarongongo entre outras, estão presentes em Aragão (1999), Destro (2002), Destro et al. (2003), entre outros. A Figura 2 apresenta o arcabouço estrutural da bacia do Recôncavo de acordo com Destro et al. (2003).

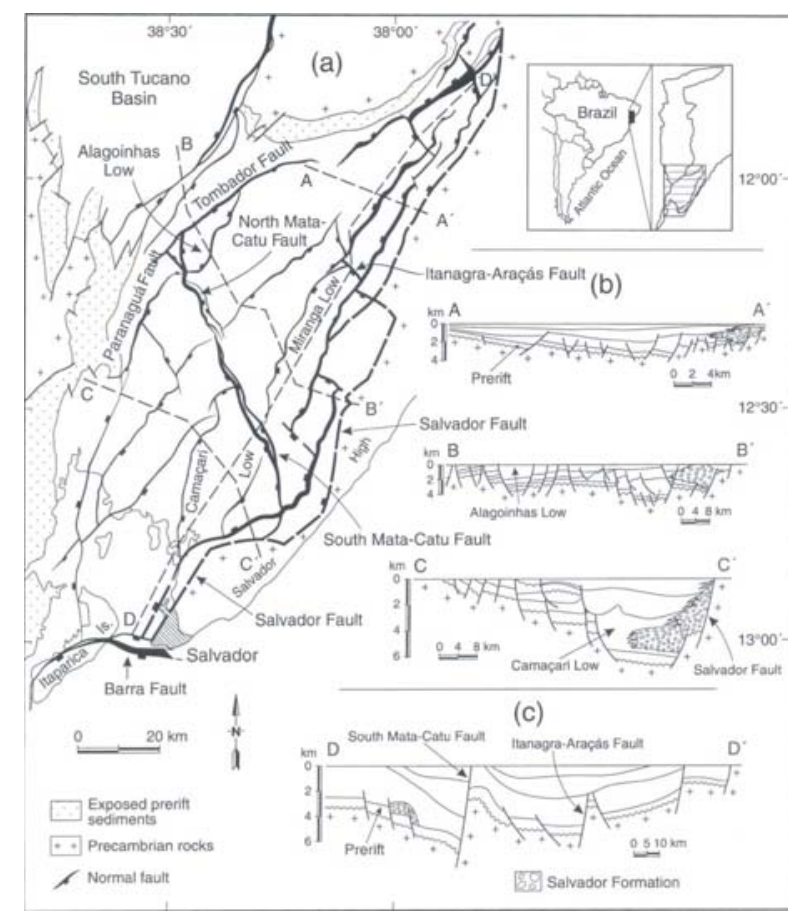

Figura 2 - Arcabouço Estrutural da Bacia do Recôncavo (Destro et al. 2003).

A evolução tectono-sedimentar, de acordo com as cartas estratigráficas revisadas das bacias do Recôncavo e Camamu, propostas por Caixeta et al. (2007) e por Silva et al. (2007), é semelhante no período incipiente para as duas bacias, diferenciando-se principalmente a partir da fase rifte, sendo que a bacia de Camamu evolui para bacia de margem passiva, e o rifte RecôncavoTucano-Jatobá é abortado precocemente. A fase sinéclise para as duas bacias é representada pelos Membros Pedrão e Cazumba da Formação Afligidos. O estágio pré-rifte da Bacia do Recôncavo é representado pelos Membros Boipeba e Capianga da Formação Aliança, e pelas Formações Sergi, Itaparica e Água Grande, estando as mesmas presentes também na bacia de Camamu, somadas ao Membro Tauá da Formação Candeias. O estágio rifte da bacia do Recôncavo é representado pelos Membros Gomo e Tauá da Formação Candeias, Formação Salvador, membros Pitanga e Caruaçu da Formação Maracangalha, Formação Marfim, Formação Pojuca, Formação Taquipe e Formação São Sebastião. Já a fase rifte da Bacia de Camamu é representada pelos Membros Jiribatuba e Tinharé da Formação Morro do Barro, Membros Ilhéus e Mutá da Formação Rio de Contas e pelo Membro Itacaré da Formação Taipus-Mirim.

Como na área alvo deste trabalho predominam as sequência pré-rifte e rifte, serão omitidas aqui a fase pósrifte da Bacia do Recôncavo e as fases pós-rifte e drift da Bacia de Camamu, sendo que Silva et al. (2007) e Caixeta et al. (2007) apresentam uma discussão detalhada sobre as cartas estratigráficas das Bacias do Recôncavo e Camamu, respectivamente.

\section{Área de Estudo e Base de Dados}

A base de dados utilizada para a realização deste estudo consta de 20 linhas sísmicas 2D (onshore, zona de transição e offshore) e 10 poços exploratórios (onshore e offshore), sendo todos de domínio público e cedidos pela Agência Nacional do Petróleo, Gás natural e Biocombustíveis (ANP), através do programa de cessão de dados públicos para universidades, sendo este trabalho parte integrante do projeto de mestrado do primeiro autor.

A área de estudo abrange a ilha de Itaparica e partes da baia de Todos os Santos e costa atlântica, como pode ser visto na Figura 2.

$\mathrm{Na}$ região da ilha de Itaparica predominam afloramentos pertencentes à fase rifte da evolução tectônica da Bacia, com destaque para os afloramentos dos turbiditos e ritmitos da Formação Maracangalha, próximos a Bom Despacho. No restante da ilha predominam coberturas cenozóicas e cordões litorâneos, havendo grande escassez de afloramentos. Entretanto, a parte continental a oeste da llha é provida de excelentes afloramentos principalmente das Formações Sergi e Aliança, predominando desse modo sequências do pré-rifte da Bacia do Recôncavo.

O potencial petrolífero da região abrange hoje o campo de Itaparica no extremo norte da ilha, bem como as acumulações marginais de Morro do Barro, Jiribatuba e 
Gamboa, contando com dezenas de poços descobridores e com indícios de óleo e gás, perfurados em sua maioria entre as décadas de 1960 e 1980, sendo ainda necessário estudos principalmente a respeito das acumulações marginais, com emprego de novas tecnologias geofísicas, como discutido por Botelho (2009).

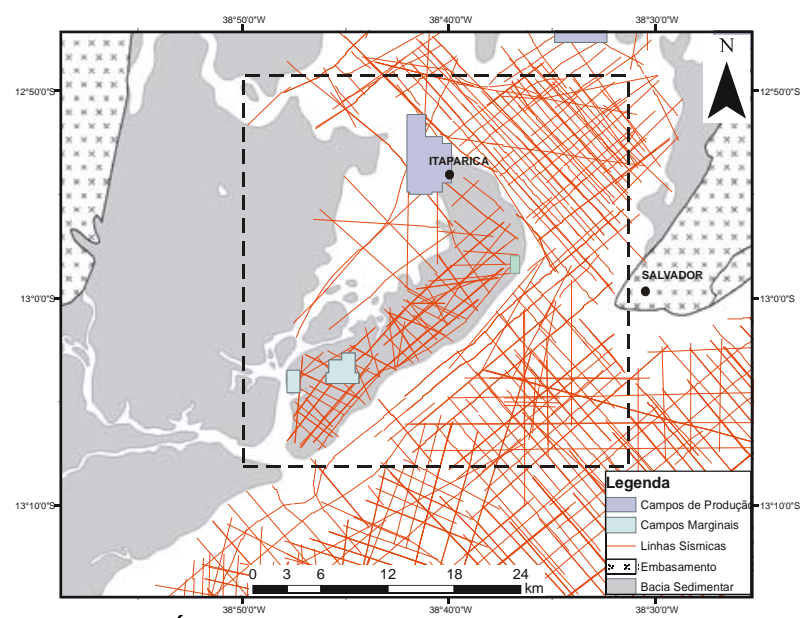

Figura 3 - Área de estudo e base de dados sísmicos de domínio público existentes no banco de dados da ANP. Fonte: BDEP.

\section{Interpretação dos Dados}

Devido às linhas sísmicas utilizadas serem oriundas de diferentes equipes de aquisição e terem sido adquiridas em diferentes épocas, foi necessário um pré-tratamento dos dados, como re-amostragem dos dados e aplicação de técnicas de filtragem pós-empilhamento e ganhos de amplitudes. A etapa de re-amostragem dos dados foi fundamental neste caso, devido a dados registrados com razão de amostragem tanto de 2 ms como 4 ms.

$\mathrm{Na}$ Figura 4 é possível visualizar sistemas de falhas sintéticas controlando a disposição das seqüências do pré-rifite e também do embasamento na parte oeste da área de estudo.

A Figura 5 apresenta uma linha sísmica onshore orientada SW-NE, ao longo da Ilha, onde é possível acompanhar a disposição do embasamento e o comportamento das seqüências sedimentares, possivelmente afetadas pelo desenvolvimento da falha transversal da Barra, separando as Bacias do Recôncavo e Camamu.

A Figura 6 apresenta linha sísmica orientada NW-SE na bahia de Todos os Santos, atravessando todo a região norte da área de estudo em direção a borda leste da bacia. Ela ilustra muito bem a configuração tectônica da bacia, em forma de meio graben assimétrico, com depocentro próximo a margem leste, cuja atividade tectônica 'foi fortemente influenciada pelo sistema de falhas de Salvador, sendo possível visualizar a falha de borda e demais falhas sintéticas e antitéticas. Tal seção assemelha-se ao perfil C-C'da Figura 2, proposta por Destro et al. (2003).
Já a Figura 7 mostra uma seção sísmica orientada SWNE disposta ao longo da costa atlântica da Ilha, sendo possível observar padrões de sedimentação próximos a 3s, sendo marcadas por uma abrupta descontinuidade lateral das camadas, possivelmente relacionadas com o alto de salvador, lembrando estruturas relacionadas a comportamentos autóctones de diápiros de argila ou evaporíticos (?).

\section{Conclusões}

A interpretação das linhas sísmicas 2D permitiu visualizar importantes estruturas rúpteis na área de estudo, com destaque para o sistema de falhas transversais da Barra e o sistema de falhas de Salvador.

Quanto à falha da Barra, têm-se que frisar a dificuldade de identificação da mesma nas seções sísmicas, e a carência de estudos específicos sobre 0 seu comportamento cinemático e o controle que a mesma exerceu na sedimentação e estruturação das bacias do Recôncavo e Camamu.

Quanto ao arcabouço tectono-estratigráfico da área, as linhas sísmicas mostraram-se bastante úteis para o entendimento do comportamento, principalmente do embasamento da bacia, confirmando a disposição de um gráben assimétrico do extremo sul da bacia do Recôncavo, com seu depocentro a leste, em direção ao alto de Salvador.

Ressalta-se que com a futura inclusão das informações dos poços e a interpretação de novas linhas sísmicas, espera-se amarrar com os dados sísmicos interpretados, trazendo maior confiabilidade e aumentando o conhecimento geológico da área. Vale citar que a base de dados disponível provém em sua grande maioria de esforços exploratórios realizados pela Petrobras entre as décadas de 1960 e 1980, sendo a qualidade dos dados a principal dificuldade enfrentada no desenvolvimento do presente trabalho.

\section{Agradecimentos}

Os autores agradecem à Agência Nacional do Petróleo pela disponibilização e autorização para uso dos dados sísmicos e de poços. O primeiro autor agradece ao colega Paulo de Tarso Antunes pela valiosa contribuição bibliográfica.

\section{Referências}

Alkimim, F. F. O que faz de um cráton um cráton? O cráton do São Francisco e as relações almeideanas ao delimitá-lo. Geologia do continente sul americano: evolução e obra de Fernando Flávio Marques de Almeida. São Paulo: Beca, 2004. P. 17-35.

Aragão, M.A.N.F.,1999. Influence of compressive stress on the structure of the Recôncavo-Tucano-Jatobá Rift and on the tectonic control of its petroleum accumulations. SNET, 7, Lençóis, 55-59.

Barbosa, J. F. S. \& Corrêa-Gomes, L. C. 2003. I Workshop sobre o Orógeno Itabuna-Salvador-Curaça - I WOISC. Geologia e guias de excursão de Campo. 
Revista Brasileira de Geociências, 33 (1-suplemento): p1:88.

Botelho, M.A.B., 2009, As novas tecnologias geofísicas e os campos marginais do Estado da Bahia. In: Ferreira (org.) Produção de Petróleo e Gás em Campos Marginais. UFBA/ANP/IBP. pp: 354-369.

Caixeta, J. M., Milhomem, P. S., Witzke, R. E., Dupuy, I. S. S., Gontijo, G. A., 2007. Boletim de Geociências da Petrobras, Rio de Janeiro, vol. 15, n.2: 455-461, maio/Nov.2007.

Destro, N., 2002. Falhas de Alívio e de transferência: o significado tectônico e economic no Rifte do RecôncavoTucano-Jatobá, NE Brasil. Universidade Federal de Ouro Preto, Tese (Doutorado), 173p.
Destro, N., Szatmari, P., Alkmim, F. F., Magnavita, L. 2003. Release fauts, associated structures, and their control on petroleum trends in the Recôncavo rift, northeast Brazil:. AAPG Bulletin. V. 87. $n^{\circ} .7$ (july 2003). p. $1123-1144$.

Magnavita, L.P., 1992. Geometry and Kinematics of the Recôncavo-Tucano-Jatobá Rift, NE Brazil. Oxford University, Ph. D. Thesis, 493p.

Silva, O. B., Caixeta, J. M., Milhomem, P. S., Kosin, M. D. Boletim de Geociências da Petrobras, Rio de Janeiro, v. 15, n.2, p 423-431, maio/Nov.2007.

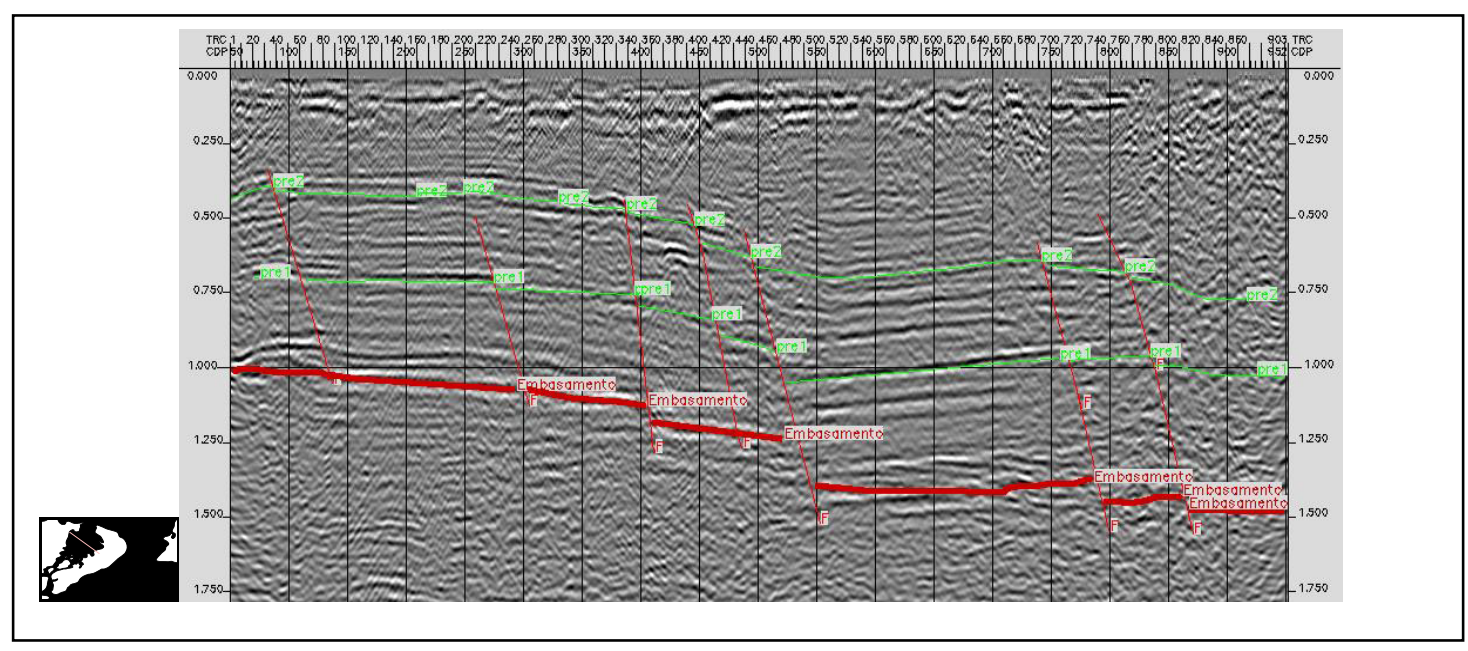

Figura 4 - Seção sísmica NW-SE interpretada, onde pode ser observado o padrão de falhas sintéticas em direção ao depocentro da bacia.

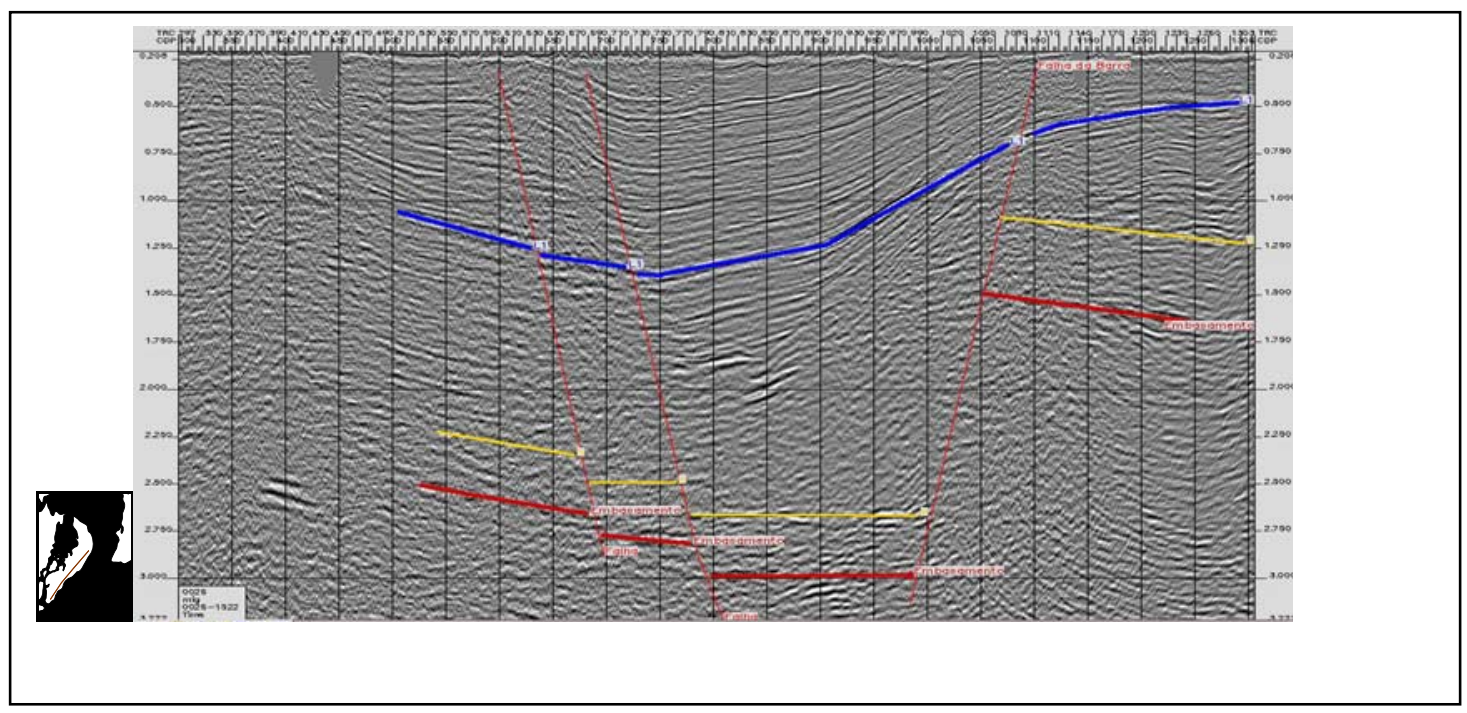

Figura 5 - Seção sísmica SW-NE, com destaque para a falha da Barra no canto direito da seção. 


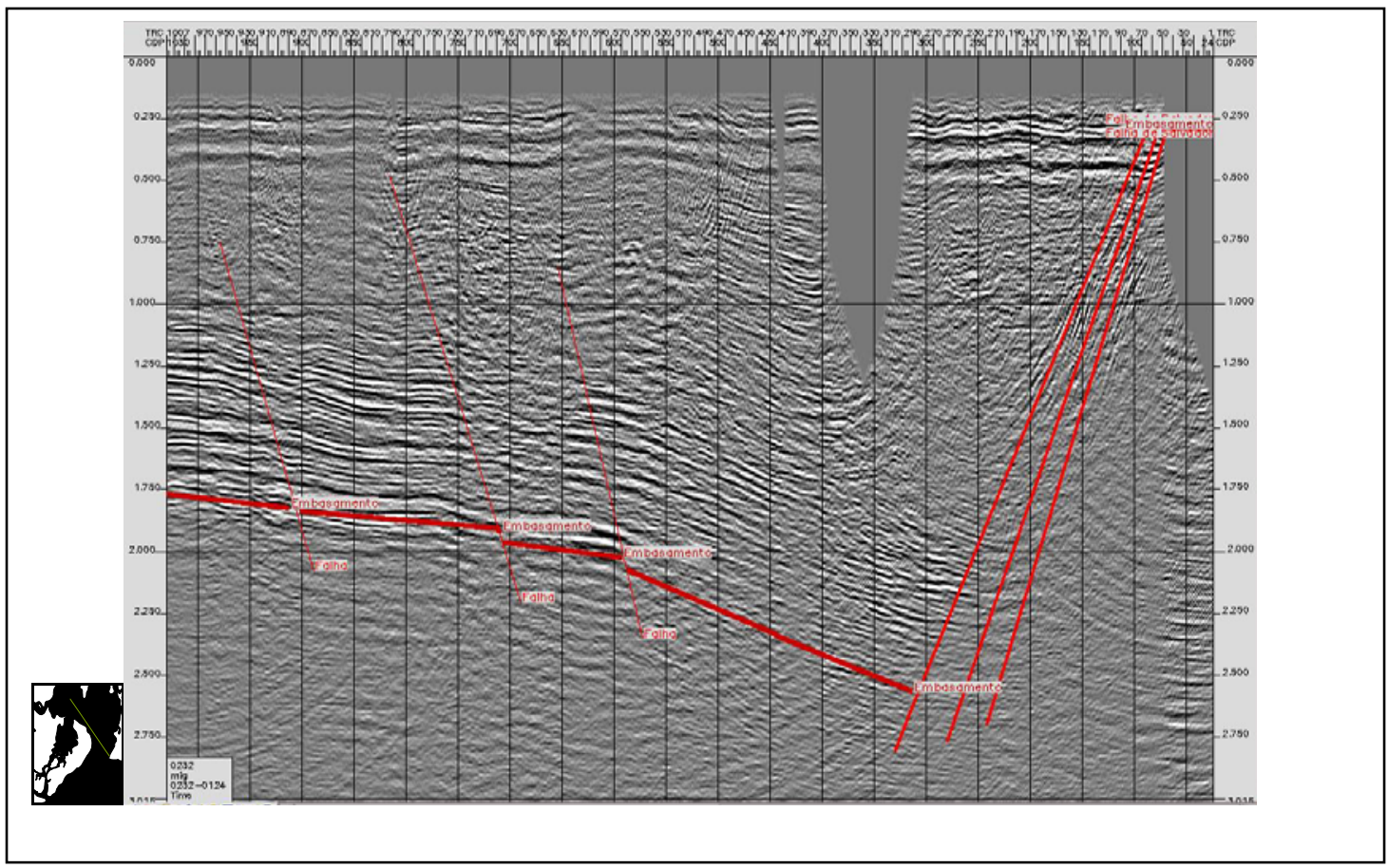

Figura 6 - Seção sísmica NW-SE, destacando a configuração de graben assimétrico da bacia, com o depocentro próximo a borda leste,ilustrada pela falha de Salvador no canto direito da seção .



Figura 7 - Seção sísmica SW-NE ao longo da costa atlântica da llha, onde pode ser observada forte descontinuidade lateral das reflexões no canto direito da seção. Tal feição que se assemelha a comportamentos autóctones de diápiros de argila ou sal, pode estar relacionado ao alto de Salvador. 